\title{
Clinical and MRI phenotypes of sarcoidosis-associated myelopathy
}

Olwen C. Murphy, MBBCh, MRCPI, Andrea Salazar-Camelo, MD, Jorge A. Jimenez, MD, Paula Barreras, MD, Maria I. Reyes, MD, Maria A. Garcia, MD, David R. Moller, MD, Edward S. Chen, MD, and Carlos A. Pardo, MD

Neurol Neuroimmunol Neuroinflamm 2020;7:e722. doi:10.1212/NXI.0000000000000722

\section{Abstract}

\section{Objective}

To determine the characteristic clinical and spinal MRI phenotypes of sarcoidosis-associated myelopathy (SAM), we analyzed a large cohort of patients with this disorder.

\section{Methods}

Patients diagnosed with SAM at a single center between 2000 and 2018 who met the established criteria for definite and probable neurosarcoidosis were included in a retrospective analysis to identify clinical profiles, CSF characteristics, and MRI lesion morphology.

\section{Results}

Of 62 included patients, 33 (53\%) were male, and 30 (48\%) were African American. SAM was the first clinical presentation of sarcoidosis in 49 patients (79\%). Temporal profile of symptom evolution was chronic in $81 \%$, with sensory symptoms most frequently reported (87\%). CSF studies showed pleocytosis in $79 \%$ and CSF-restricted oligoclonal bands in $23 \%$ of samples tested. Four discrete patterns of lesion morphology were identified on spine MRI: longitudinally extensive myelitis $(n=28,45 \%)$, short tumefactive myelitis $(n=14,23 \%)$, spinal meningitis/meningoradiculitis $(n=14,23 \%)$, and anterior myelitis associated with areas of disc degeneration $(n=6,10 \%)$. Postgadolinium enhancement was seen in all but 1 patient during the acute phase. The most frequent enhancement pattern was dorsal subpial enhancement $(\mathrm{n}=$ $40)$, followed by meningeal/radicular enhancement $(n=23)$ and ventral subpial enhancement $(\mathrm{n}=12)$. In 26 cases $(42 \%)$, enhancement occurred at locations with coexisting structural changes (e.g., spondylosis).

\section{Conclusions}

Recognition of the clinical features (chronically evolving myelopathy) and distinct MRI phenotypes (with enhancement in a subpial and/or meningeal pattern) seen in SAM can aid diagnosis of this disorder. Enhancement patterns suggest that SAM may have a predilection for areas of the spinal cord susceptible to mechanical stress.

\author{
Correspondence \\ Dr. Pardo \\ cpardov1@jhmi.edu
}




\section{Glossary}

BSCB = blood-spinal cord barrier; IQR = interquartile range; $\mathbf{m R S}=$ modified Rankin Scale; NMOSD = neuromyelitis optica spectrum disorder; SAM = sarcoidosis-associated myelopathy.

Sarcoidosis is a multisystem disorder of uncertain etiology characterized pathologically by granulomatous inflammation in the absence of pathogenic microorganisms. Neurologic involvement occurs in approximately $5 \%$ of cases and may involve the meninges, cranial nerves, hypothalamus, pituitary gland, brain parenchyma, spinal cord, or peripheral nerves. ${ }^{1,2}$ In approximately half of patients with neurosarcoidosis, the neurologic symptoms represent the first clinical manifestation of sarcoidosis. ${ }^{1}$ However, it is not well understood why some patients with sarcoidosis develop neurologic manifestations, and others do not. In the CNS, the meninges are populated by multiple immune cell types and lymphatic vessels ${ }^{3}$ and are frequently involved in neurosarcoidosis. ${ }^{1,2,4}$ It has been postulated that parenchymal CNS involvement may result from extension of leptomeningeal-based inflammation along perivascular spaces surrounding small- and medium-sized arteries and veins. ${ }^{5-7}$

Sarcoidosis-associated myelopathy (SAM) represents a particular diagnostic challenge as many of the clinical and radiologic features may overlap with other inflammatory spinal cord disorders such as neuromyelitis optica spectrum disorder (NMOSD). Indeed, misdiagnosis is common in patients with myelopathic disorders, and physicians frequently fail to recognize neurosarcoidosis as a specific cause of myelitis. ${ }^{8,9}$ Thus, identifying characteristic clinical, imaging, and CSF features of SAM is critically important to facilitate timely diagnosis and treatment. Previous studies have identified features to differentiate longitudinally extensive myelitis of neurosarcoidosis from NMOSD, ${ }^{10}$ including the trident sign $^{11}$; however, nonlongitudinally extensive SAM lesions have not been well described. Furthermore, studies examining the spectrum of spinal cord involvement in neurosarcoidosis have been limited by small numbers. ${ }^{12,13}$ Here, we aim to characterize the clinical, radiologic, and CSF profiles of a large cohort of patients with SAM.

\section{Methods}

\section{Study design and participants}

We retrospectively identified patients diagnosed with SAM between 2000 and 2018 at the Johns Hopkins Myelitis and Myelopathy Center. We included patients with definite neurosarcoidosis (with pathologic confirmation of granulomatous disease in the nervous system) or probable neurosarcoidosis (with pathologic confirmation of systemic granulomatous disease) according to the diagnostic criteria outlined in 2018 by the Neurosarcoidosis Consortium Consensus Group. ${ }^{14}$ To fulfill these diagnostic criteria, the clinical manifestations and findings of MRI, CSF, and/or EMG/nerve conduction studies must suggest granulomatous inflammation of the nervous system, after rigorous exclusion of other causes. ${ }^{14}$ We excluded patients with possible neurosarcoidosis, i.e., patients without any pathologic confirmation of granulomatous disease. All diagnoses were made by a neuroimmunologist with clinical expertise in neurosarcoidosis and inflammatory myelopathies (C.A.P.). Spinal cord involvement was defined by (1) a clinical presentation suggestive of myelopathy and (2) the presence of an associated intra- or extra-medullary lesion identified on spine MRI. We excluded patients in whom MRI with and without contrast from the acute phase of the myelopathy was not available for review or in whom another cause for myelopathy was deemed more likely.

\section{Demographic and clinical characteristics}

Information was acquired from the medical records of included patients using a standardized approach previously described by our group for the evaluation of clinical, temporal, and neuroimaging profiles of myelopathies. ${ }^{9}$ Temporal profile of symptom evolution was defined as the period of time from onset of the first myelopathic symptom to the neurologic nadir, categorized as follows: (1) chronic: >3 weeks; (2) subacute: 2-21 days; (3) acute: 6-48 hours; and (4) hyperacute: $<6$ hours. Severity of neurologic disability at nadir and at approximately 1 year (12-15 months) after initial assessment was described using the modified Rankin Scale $(\mathrm{mRS})^{15}$ and the American Spinal Injury Association impairment scale. ${ }^{16}$ The date on which pathologic studies confirmed granulomatous inflammation was recorded as the date of diagnosis. Laboratory data obtained from CSF analysis during the acute phase of the myelopathy were recorded from medical records, where available.

\section{Neuroimaging}

Spine MRI with and without contrast obtained for each patient during the acute phase of the myelopathy was reviewed by 2 neurologists with expertise in myelopathies and neurosarcoidosis (O.C.M. and C.A.P.). Axial and sagittal T2 sequences were qualitatively analyzed to determine lesion morphology, lesion location, and lesion length. Longitudinal extension was defined as an intramedullary T2 hyperintense lesion spanning $>3$ contiguous vertebral segments. Axial and sagittal $\mathrm{T} 1$ postcontrast sequences were qualitatively analyzed to determine the presence or absence of enhancement and the location of enhancement (meningeal, nerve root, and ventral and/or dorsal subpial). Enhancement was considered subpial where the longitudinal extent of the enhancing area seen on sagittal images was contiguous with the surface of the spinal cord on axial images (e.g., an enhancing area spanning 3 vertebral segments on sagittal images was contiguous with the surface of the cord within each of the 3 vertebral segments). Images from previously published studies of subpial enhancement in spinal cord sarcoidosis were used as a guide. ${ }^{10,11,17}$ In addition, all axial postcontrast sequences were specifically evaluated for the trident sign. ${ }^{11}$ The lesion patterns described in the results herein were not predetermined; rather, they were identified during the 
analysis process by the first imaging reviewer (O.C.M.), and these patterns and according lesion categorizations were validated by the second imaging reviewer (C.A.P.).

\section{Statistical analysis}

Statistical analyses were performed using Stata version 13 (StataCorp, College Station, TX) to examine for differences in age, sex, race, and time to diagnosis between patients categorized by MRI lesion pattern. The Wilcoxon rank-sum test, $\chi^{2}$ test, and one-way analysis of variance tests were used as appropriate, and $p<0.05$ was considered as significant.

\section{Ethical approval}

Johns Hopkins University Institutional Review Board approval was obtained for this study, with requirements for patient consent waived.

\section{Data availability}

Qualified investigators may request access to anonymized data relevant to this study, pending appropriate institutional review board approvals.

\section{Results}

\section{Demographic characteristics}

Of 104 patients diagnosed with SAM at the Johns Hopkins Myelitis and Myelopathy Center during the period 2000-2018, 74 patients had a spine MRI with and without contrast obtained during the initial assessment of the myelopathy available for review. Twelve of these patients were excluded due to lack of biopsy confirmation of granulomatous disease (possible neurosarcoidosis), leaving 62 patients for analysis. Fifty-four patients were diagnosed with probable neurosarcoidosis (36 by lymph node biopsy, 16 by lung biopsy, and 2 by other biopsy sites), whereas 8 patients had definite neurosarcoidosis ( 4 by spinal cord biopsy, 3 by brain biopsy, and 1 by meningeal biopsy). In the 4 patients who underwent spinal cord biopsy, pathology demonstrated nonnecrotizing granulomatous inflammation. Mean age of our cohort was 47 years (SD 11), 33 patients (53\%) were male, and $30(48 \%)$ were African American (table 1). Thirteen patients (21\%) had an existing diagnosis of sarcoidosis (either systemic sarcoidosis and/or neurosarcoidosis) before onset of myelopathic symptoms. In other words, SAM was the first clinical presentation of sarcoidosis in 49 patients (79\%).

\section{Clinical profiles}

Temporal profile of symptom onset was chronic in the majority of patients ( 50 patients, $81 \%$ ), and sensory abnormalities were the most frequently reported symptoms ( 54 patients, $87 \%$, table 1). There was a substantial delay to clinical presentation in many cases (table 1), with 12 patients (19\%) reporting symptoms present for over 1 year before their first evaluation by a neurologist. Involvement of other areas of the nervous system beyond the spinal cord was identified in 16 patients $(25 \%)$. For patients without a diagnosis of sarcoidosis before the onset of myelopathic symptoms ( 49 of 62 patients), the mean time from the onset of myelopathic symptoms to diagnosis of neurosarcoidosis was 5 months (range 1-50 months). Disability was measured using the mRS for 34 patients who underwent both initial evaluation and repeat assessment 1 year later (range 12-15 months). At baseline, 18 of 34 patients (52\%) had an $\mathrm{mRS}$ score of 3 or higher, indicating at least a moderate level of disability/dependence (supplemental figure 1, links.lww.com/ NXI/A236). At follow-up 1 year later, the mRS score had improved in 50\% (17 patients), worsened in 26\% (9 patients), and remained stable in $24 \%$ ( 8 patients).

\section{CSF findings}

CSF studies were available for 43 patients. Pleocytosis was identified in 34 of 43 patients (79\%), with a median white blood cell count of 43 per $\mathrm{mm}^{3}$ (interquartile range [IQR] $16-88$ per $\mathrm{mm}^{3}$ ) in these patients (median $97 \%$ lymphocytes, IQR 92\%-100\%). Protein was elevated in 32 patients $(74 \%$, with a median protein level of $69 \mathrm{mg} / \mathrm{dL}$, range $12-687 \mathrm{mg} /$ dL). Oligoclonal bands were analyzed in 30 patients, and CSF-restricted bands were identified in 7 cases (23\%), whereas CSF immunoglobulin G index was analyzed in 29 cases and was elevated in 5 (17\%). Median CSF glucose tested in 40 patients was $50 \mathrm{mg} / \mathrm{dL}$ (range $15-150 \mathrm{mg} / \mathrm{dL}$ ), with 11 patients $(28 \%)$ having a low CSF glucose level $(<45 \mathrm{mg} / \mathrm{dL})$.

\section{MRI lesion morphology and enhancement patterns}

The most frequently identified SAM lesion type on MRI was longitudinally extensive myelitis $(n=28$ patients [ $44 \%$ ], figure 1$)$, associated with dorsal subpial enhancement $(n=26)$ and/or ventral subpial enhancement $(n=5)$. Longitudinally extensive myelitis lesions spanned a median of 6 vertebral segments (IQR 4-7.5). The second MRI lesion type was short tumefactive myelitis, identified in 14 patients (23\%, figure 1 ). The third lesion type was spinal meningitis/meningoradiculitis with enhancement restricted to extramedullary structures, seen in 14 patients $(23 \%$, figure 1). Although some patients with spinal meningitis/ meningoradiculitis had patchy or subtle T2 signal changes within the cord, the enhancement was strictly extramedullary. However, meningeal or radicular enhancement was also observed in conjunction with subpial enhancement in another 9 patients (i.e., in association with a longitudinally extensive or short tumefactive myelitis lesion, categorized in table 2). An unusual and distinct pattern of anterior myelitis occurring at locations of disc degeneration was identified in 6 patients (10\%, figure 2$)$, all with ventral subpial enhancement. Finally, 1 patient with probable neurosarcoidosis had a small ovoid lesion, which was not enhancing at any point and which we labeled atypical (table 2).

Enhancement was present in 61 of 62 cases at the time of diagnosis of SAM, regardless of how long the delay to diagnosis was. Across lesion types, subpial enhancement frequently occurred at locations with coexisting structural changes such as disc herniations or cervical spondylosis, i.e., in areas of the spinal cord that could be considered susceptible to mechanical stress $(n=26$ [42\%], figure 2). Six patients with coexisting severe cervical spondylosis underwent surgical 
Table 1 Demographic and clinical characteristics of the study population

\begin{tabular}{|c|c|}
\hline & Subjects $(n=62)$ \\
\hline Male, \% & $33(53 \%)$ \\
\hline Mean age, yr (SD) & $47(11)$ \\
\hline \multicolumn{2}{|l|}{ Race } \\
\hline Caucasian & $29(47 \%)$ \\
\hline African American & $30(48 \%)$ \\
\hline Other & $3(5 \%)$ \\
\hline Previous diagnosis of sarcoidosis & $13(21 \%)$ \\
\hline Family history of sarcoidosis & $10(16 \%)$ \\
\hline \multicolumn{2}{|l|}{ Temporal profile of myelopathic symptom evolution } \\
\hline Chronic (>3 wk to neurologic nadir) & $50(81 \%)$ \\
\hline Subacute (2-21 d to neurologic nadir) & $9(14 \%)$ \\
\hline Acute $(6-48 \mathrm{~h}$ to neurologic nadir) & $3(5 \%)$ \\
\hline \multicolumn{2}{|l|}{ Time from symptom onset to first neurologist evaluation } \\
\hline$<3 \mathbf{w k}$ & $13(21 \%)$ \\
\hline $3 \mathrm{wk}$ to $3 \mathrm{mo}$ & $20(32 \%)$ \\
\hline 3-12 mo & $17(27 \%)$ \\
\hline$>12 \mathrm{mo}$ & $12(19 \%)$ \\
\hline \multicolumn{2}{|l|}{ Myelopathic symptoms } \\
\hline Sensory symptoms & $54(87 \%)$ \\
\hline Motor symptoms & $33(53 \%)$ \\
\hline Bladder/bowel dysfunction & $19(31 \%)$ \\
\hline Patients with multiple areas of neurosarcoidosis involvement ${ }^{a}$ & $16(25 \%)$ \\
\hline Intracranial meningitis & $10(16 \%)$ \\
\hline Encephalitis & $9(14 \%)$ \\
\hline Cranial neuropathies & $4(6 \%)$ \\
\hline Hypophysitis & $1(2 \%)$ \\
\hline Myopathy & $1(2 \%)$ \\
\hline
\end{tabular}

decompression in addition to medical management of sarcoidosis (in 2 patients, surgery preceded diagnosis of SAM, and in 4 patients, surgery was undertaken after diagnosis and treatment of SAM). A relationship with areas of mechanical stress was not observed in patients with enhancement strictly restricted to meninges or nerves roots (spinal meningitis/ meningoradiculitis). The previously described trident $\operatorname{sign}^{11}$ was identified in 6 cases overall (9\%; 4 with longitudinally extensive myelitis and 2 with short tumefactive myelitis).

The vertebral locations of intramedullary $\mathrm{T} 2$ hyperintensity in patients with longitudinally extensive myelitis, short tumefactive myelitis, or anterior myelitis with disc degeneration are outlined in figure 3. Longitudinally extensive myelitis typically involved the cervical cord (24 of 28 cases, $86 \%$ ), with or without extension into the thoracic cord. Short tumefactive myelitis was most frequently seen in the cervical cord (9 of 14, 64\%) or lower thoracic cord/conus medullaris (3 of 14, 21\%). Anterior myelitis with disc degeneration was only seen in the thoracic cord, and 2 of these lesions spanned $>3$ contiguous segments but still displayed a recognizably distinct morphology compared with the first pattern we have described of typical longitudinally extensive myelitis lesions. 

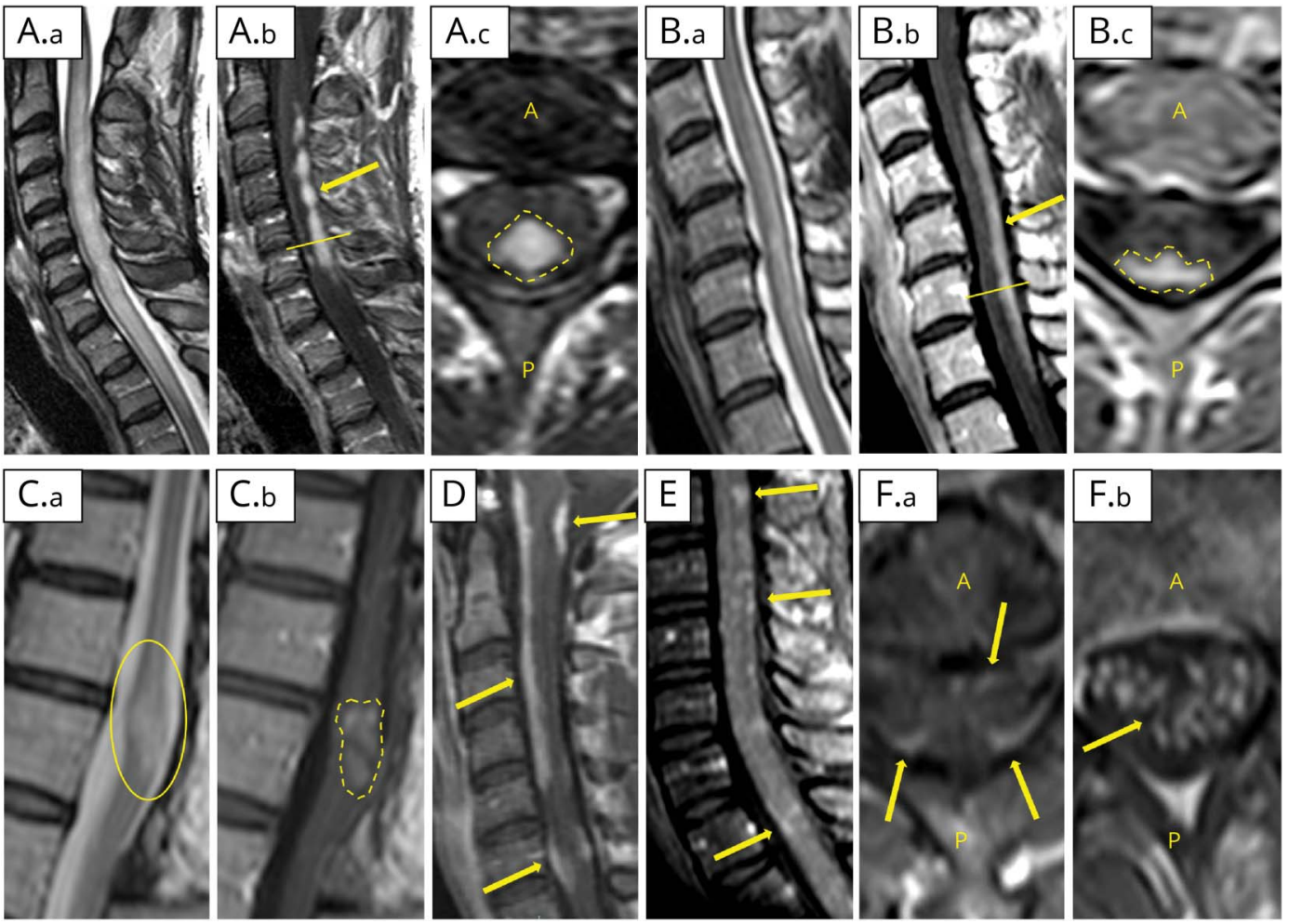

(A) In this patient, intramedullary high T2 signal spans the cervical and upper thoracic spinal cord (A.a = sagittal T2), with extensive enhancement in a dorsal subpial distribution, indicated by the yellow arrow in A.b and the yellow dotted line in A.c (A.b = sagittal T1 fat saturation postgadolinium, A.c = axial T1 postgadolinium, with axial location indicated by the yellow line in panel B). (B) This longitudinally extensive myelitis lesion spans from C2 to C7 (B.a = sagittal T2), again with extensive dorsal subpial enhancement, indicated by the yellow arrow in B.b (B.b = sagittal T1 postgadolinium). On axial T1 postcontrast enhancement resembles the trident sign (outlined by the yellow dotted line), without central canal enhancement (B.c with axial location indicated by the yellow line in panel B.b). (C) In this patient, a bulky lesion is demonstrated in the lower thoracic spinal cord, highlighted by the yellow circle (C.a = sagittal T2), with associated dorsal-predominant patchy enhancement, outlined by the yellow dotted line (C.b = sagittal T1 postgadolinium). The radiology report (before diagnosis of sarcoidosis) suggested an intrinsic spinal cord tumor as the most likely diagnosis. (D) Bulky pachymeningeal disease can be seen in the cervical region in this patient on sagittal T1 postgadolinium sequence. (E) Enhancement (highlighted by yellow arrows) is present in a nodular leptomeningeal pattern (sagittal T1 fat saturation postgadolinium image of the cervical region) in a patient with spinal meningitis. (F) Avid nerve root enhancement is present in the cervical ventral and dorsal nerve roots (F.a = axial T1 postgadolinium image at the level of C5, with yellow arrows indicating enhancement of the left anterior, left posterior, and right posterior spinal nerve roots) and in the cauda equina (F.b = axial T1 postgadolinium at the level of L1, with the yellow area indicating the enhancing nerve roots) of this patient.

In the 49 patients without a preexisting diagnosis of sarcoidosis, time to diagnosis was shortest in patients with longitudinally extensive myelitis (median 4 months, range 1-13 months) compared with patients with short tumefactive myelitis (median 5 months, range 1-32 months), spinal meningitis/meningoradiculitis (median 7 months, range 1-50 months), or anterior myelitis with disc herniation (median 15.5 months, range 2-36 months, $p=0.004$ across categories, figure 3 ). In analysis of associations between lesion pattern and age, sex, or race, the only significant association identified was that patients with anterior myelitis with disc degeneration were younger than patients with other lesion patterns (mean 38.3 years [SD 8.5] vs 47.7 years [SD 10.6], $p=0.03$ ).

\section{Discussion}

We have described the clinical characteristics, CSF findings, and distinct neuroimaging phenotypes seen in a cohort of 62 patients with SAM. Epidemiologic and clinical factors may act as clues to the diagnosis of SAM. The incidence of sarcoidosis is known to be increased in African Americans, ${ }^{18}$ and in recent years, the genetic contribution to sarcoidosis and neurosarcoidosis risk has become more clearly elucidated. ${ }^{19,20}$ This is borne out by the substantial proportion of African American patients in our cohort $(48 \%)$ and the relatively frequent family history of sarcoidosis (16\%). Clinically, we have shown that SAM typically has a chronic temporal evolution dominated by sensory symptoms (in keeping with the dorsal-predominant location of medullary inflammation). Unsurprisingly, our study showed that CSF studies in SAM typically reveal nonspecific markers of inflammation (i.e., pleocytosis and elevated protein). However, the presence of CSF-restricted oligoclonal bands in around $20 \%$ of samples tested was a notable finding and emphasizes that differentiating SAM from other neuroinflammatory disorders based on clinical and imaging factors is crucial.

As a rare manifestation of sarcoidosis and a rare cause of myelopathy, SAM can be challenging to diagnose and may be mistaken for idiopathic transverse myelitis, ${ }^{8}$ NMOSD, ${ }^{10}$ compressive myelopathy, ${ }^{21}$ meningeal metastatic disease, ${ }^{22}$ or 
Table 2 MRI patterns of spinal cord sarcoidosis

\begin{tabular}{lllll}
\hline \multirow{2}{*}{$\begin{array}{l}\text { Lesion pattern } \\
\text { Longitudinally extensive myelitis (>3 segments) }\end{array}$} & \multicolumn{2}{l}{ Enhancement pattern ${ }^{\text {a }}$} \\
\cline { 3 - 5 } Short tumefactive myelitis & $\left.28^{\mathrm{b}} \mathbf{6 2}\right)$ & Dorsal subpial & Ventral subpial & Meningeal/radicular \\
\hline Spinal meningitis/meningoradiculitis & $14^{\mathrm{b}}$ & 26 & 5 \\
\hline Anterior myelitis with disc degeneration & 14 & 0 & 1 & 2 \\
\hline Atypical nonenhancing & 6 & 0 & 0 & 14 \\
\hline
\end{tabular}

a In some patients, more than 1 enhancement pattern was present, and each was recorded.

${ }^{\mathrm{b}}$ One patient had both longitudinally extensive myelitis in the cervical cord and a short tumefactive lesion in the conus medullaris, with lesions reported separately here.

a spinal cord tumor. ${ }^{23}$ Moreover, compared with many pathologies affecting the spinal cord, neurosarcoidosis is a treatable condition-often responding well to steroids, immunosuppressive therapies, or certain monoclonal antibodies. ${ }^{24,25}$ Of interest, although disability status of SAM in a subset of patients in our cohort showed improvement in 52\% after 1-year follow-up, almost $26 \%$ had worsening disability, a finding that may reflect the refractory and aggressive neuroinflammatory process in SAM in some patients or the delay in diagnosis and treatment that may also affect the overall outcome. Thus, it is essential for clinicians to recognize the clinical characteristics, CSF, and imaging findings associated with this disorder.

An enhancing MRI lesion was demonstrated in all but 1 patient during evaluation of their myelopathy (often many months after symptom onset), and the central findings of our study were the 4 distinct radiologic phenotypes of SAM identified. Our finding that longitudinally extensive myelitis with predominantly dorsal subpial \pm meningeal enhancement was the most common imaging pattern is in agreement with a previous study that focused on comparing longitudinally extensive lesions of SAM with NMOSD ${ }^{10}$ Taken together, these findings suggest that this can be considered the classic imaging phenotype of SAM. However, given that this MRI lesion pattern was only present in $45 \%$ of our cohort, our description of other distinct imaging phenotypes occurring in SAM is of particular importance. Short tumefactive lesions may cause the most diagnostic difficulty, and indeed, 4 of our patients with this lesion type actually underwent spinal cord biopsy (before attendance at our clinic). Spinal cord biopsy carries a risk of substantial morbidity ${ }^{26,27}$ and should be avoided except in circumstances where there is a high likelihood of a tumor. We suggest that dorsal-predominant enhancement or the trident $\operatorname{sign}^{11}$ in a tumefactive lesion should be considered clues to SAM. Once SAM is suspected, a diagnosis of sarcoidosis can usually be established based on body imaging (CT or PET-CT) and targeted systemic biopsy (most frequently of involved lymph nodes). ${ }^{1,14}$

The patterns of spinal meningeal involvement we identified in SAM are also interesting. We have shown that meningeal and/or nerve root enhancement can occur in isolation or in conjunction with frank subpial enhancement. Furthermore, although leptomeningitis is often described as typical of spinal meningitis in sarcoidosis, ${ }^{28}$ we have demonstrated that pachymeningitis also occurs, sometimes in the form of mass lesions with a substantial compressive effect on the spinal cord. In comparison to our study, some previous case series describing neurosarcoidosis have reported that spinal meningitis is far more frequent than intramedullary inflammation. ${ }^{1}$ On the one hand, this difference could be due to referral bias (our clinic is a specialist referral center), with intramedullary inflammation posing more diagnostic challenges. On the other hand, differentiating meningeal from subpial MRI enhancement can be difficult, and there is likely to be overlap in what has been described as leptomeningeal in some case series and what we (and other recent radiologic studies of SAM $)^{10}$ have described as subpial.

An intriguing and novel finding in our study was the presence of a ventral thoracic spinal cord lesion in 6 patients, with enhancement occurring in close relationship to areas of disc degeneration abutting the cord. In all of these 6 patients, clinical improvement and resolution of MRI enhancement was achieved with medical treatment alone (without surgery). A similar case has been recently described. ${ }^{17}$ Furthermore, we also noted that areas of enhancement in SAM frequently occurred at areas of structural change, such as cervical spondylosis. To help differentiate the primary disease process in these cases, subpial enhancement in SAM is typically greater in linear than transverse extent and is continuous across multiple vertebral levels, whereas the pancakelike enhancement seen in spondylotic myelopathy occurs in a transverse pattern over $\leq 1$ vertebral level. ${ }^{29}$ In some cases, both SAM and cervical spondylosis may be contributing to the clinical and neuroimaging picture-sometimes necessitating surgical decompression in addition to medical management of sarcoidosis. Indeed, the coexistence of SAM and cervical spondylosis has been previously noted in a number of small case series. ${ }^{30-32}$ Collectively, we interpret these observations as suggesting that the inflammation of SAM may have a predilection for areas of the spinal cord susceptible to mechanical stress, potentially providing clues to the pathophysiology of this condition. The impact of chronic compression of the spinal cord has been well studied in cervical spondylotic myelopathy, with chronic mechanical pressure inducing localized tissue hypoxia, persistent disruption of the blood- 

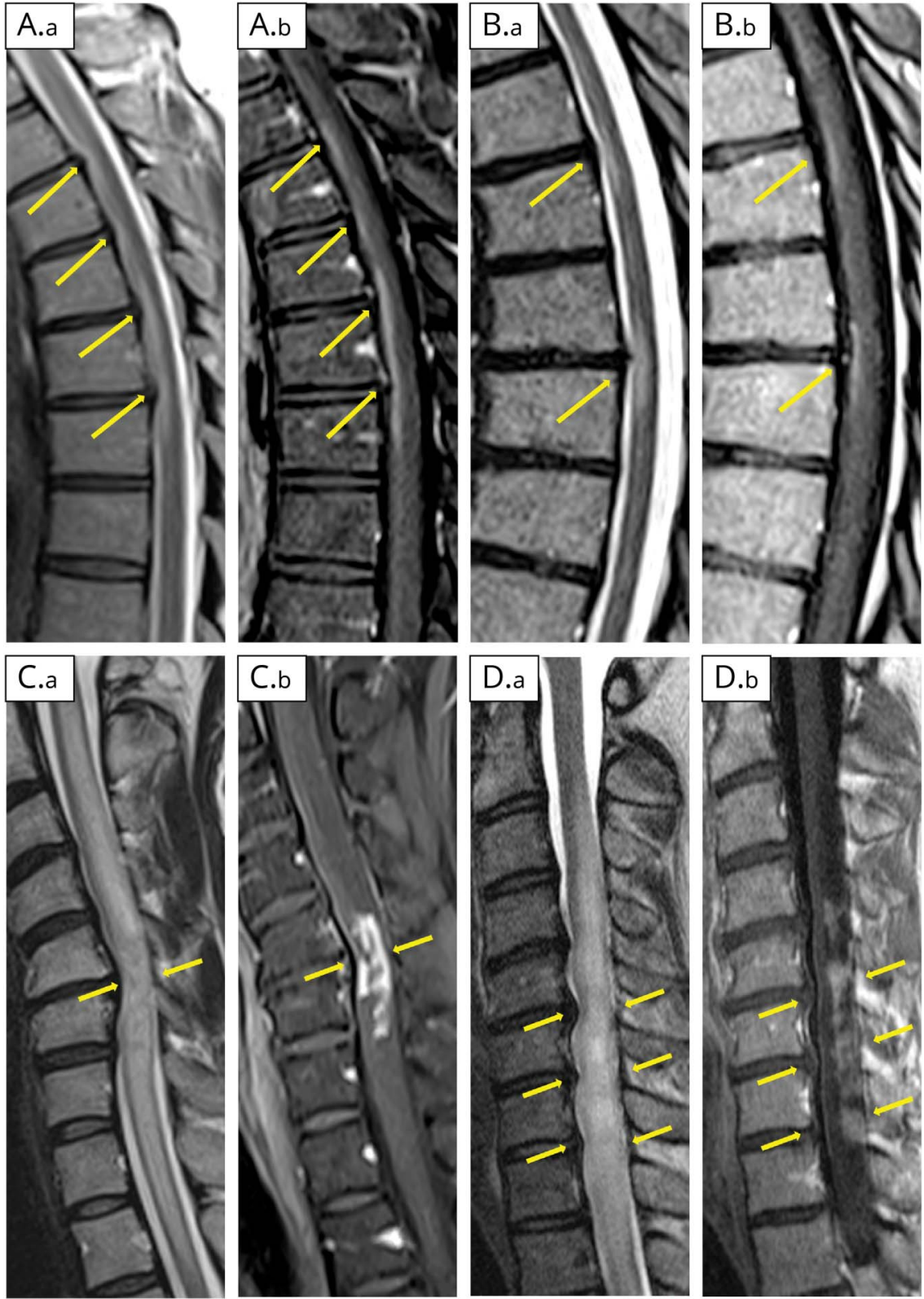

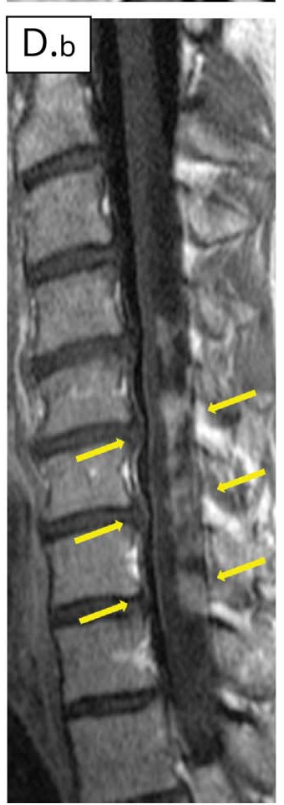

(A and B) The lesion pattern of anterior myelitis with ventral subpial enhancement occurring focally in areas of the spinal cord overlying disc degenerations is demonstrated in 2 patients here. In patient A (A.a = sagittal T2, A.b = sagittal T1 fat saturation postgadolinium), focal enhancement occurs in the spinal cord in close relationship with 4 bulging thoracic discs (arrows). A similar pattern is demonstrated in patient B (B.a = sagittal T2, B.b = sagittal $\mathrm{T} 1$ postgadolinium), with focal enhancement centered over 2 areas of disc degeneration (arrows). In all cases with this lesion pattern, patients' MRI findings and clinical symptoms improved with medical treatment of sarcoidosis, without any requirement for spinal surgery. (C and D) In patients with other lesion types, enhancement also frequently occurred in close relationship with coexisting structural changes such as degenerative disc disease or spinal stenosis. Two patients with longitudinally extensive myelitis are demonstrated here, with the areas of ventral and dorsal subpial enhancement in the spinal cord occurring in close proximity to cervical degenerative changes. In patient $C$ (C.a = sagittal T2, C.b = sagittal T1 fat saturation postgadolinium), avid enhancement is centered in the region of the cervical cord where the spinal canal is tightest, and the enhancement pattern appears to demonstrate both the linear dorsal subpial enhancement typical of sarcoidosis-associated myelopathy (SAM) and the transverse pancake-like enhancement of spondylotic myelopathy (arrows). The imaging findings suggest the coexistence of SAM and spondylotic myelopathy in this patient. In patient D (D.a = sagittal T2, D.b = sagittal T1 postgadolinium), with degenerative changes throughout the cervical spinal column, enhancement of spinal cord sarcoidosis is pronounced in this region (arrows). spinal cord barrier (BSCB), secondary inflammation (sometimes manifesting with mild CSF pleocytosis), microglial activation, and infiltration of peripheral immune cells. ${ }^{29,33,34}$ We hypothesize that in SAM, increased permeability of the BSCB at sites of mechanical stress could be a key step in the evolution of inflammatory lesions, allowing meningeal-based inflammation to spill into the parenchyma. Indeed, pathologic studies suggest that parenchymal brain and spinal cord lesions in neurosarcoidosis occur when leptomeningeal-based granulomatous inflammation (which can be present histopathologically even in the absence of clinical symptoms $)^{35}$ spreads in a perivascular distribution along smalland medium-sized vessels. ${ }^{5,36-38}$ Our finding that medullary enhancement in SAM was always contiguous with the surface of the spinal cord supports this theory. Of interest, the spinal meningeal lymphatics are thought to be predominantly dorsally situated, 3,39 where the BSCB is also thought to be most permeable ${ }^{10}$ and where subpial enhancement is most frequent in SAM. In addition, longitudinally extensive myelitis of SAM has many radiologic similarities to lesions of NMOSD - a disease characterized by extensive BSCB disruption. ${ }^{40}$ We suggest that BSCB disruption in SAM may not simply be a secondary effect of focal inflammation, but could actually be an important factor in the development and localization of medullary granulomatous lesions.

We found that time to diagnosis was shortest in patients with longitudinally extensive myelitis. This may be because the clinical syndrome is severe and the radiologic features in these lesions are recognized as typical for SAM, prompting appropriate 


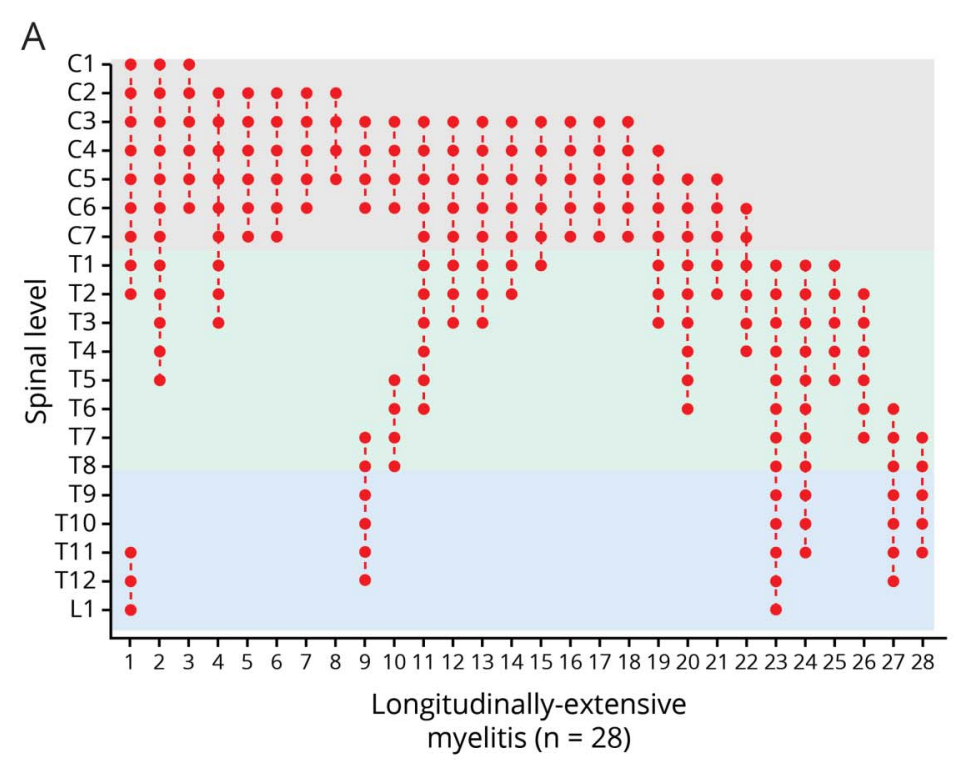

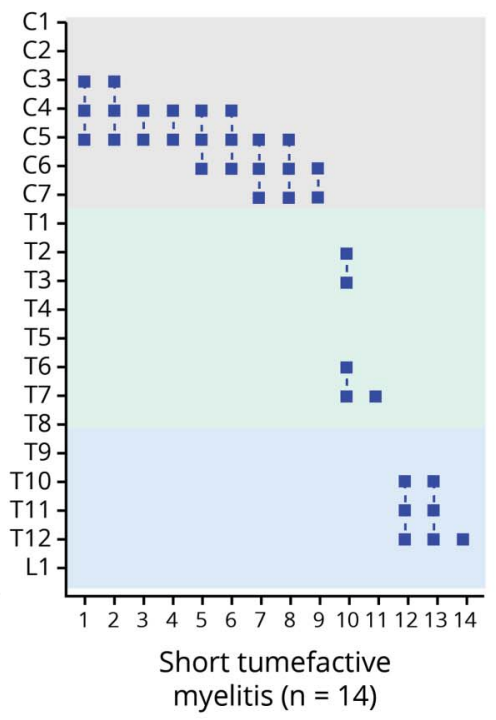

myelitis $(n=14)$

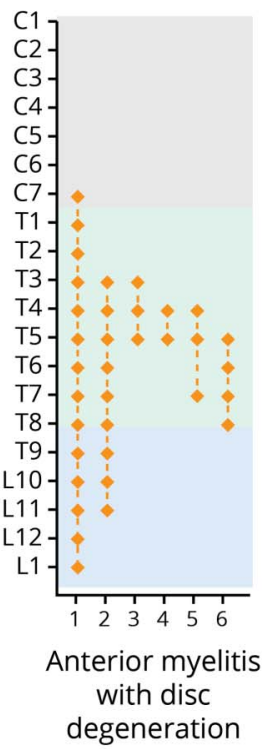

$(n=6)$

$\mathrm{B}$

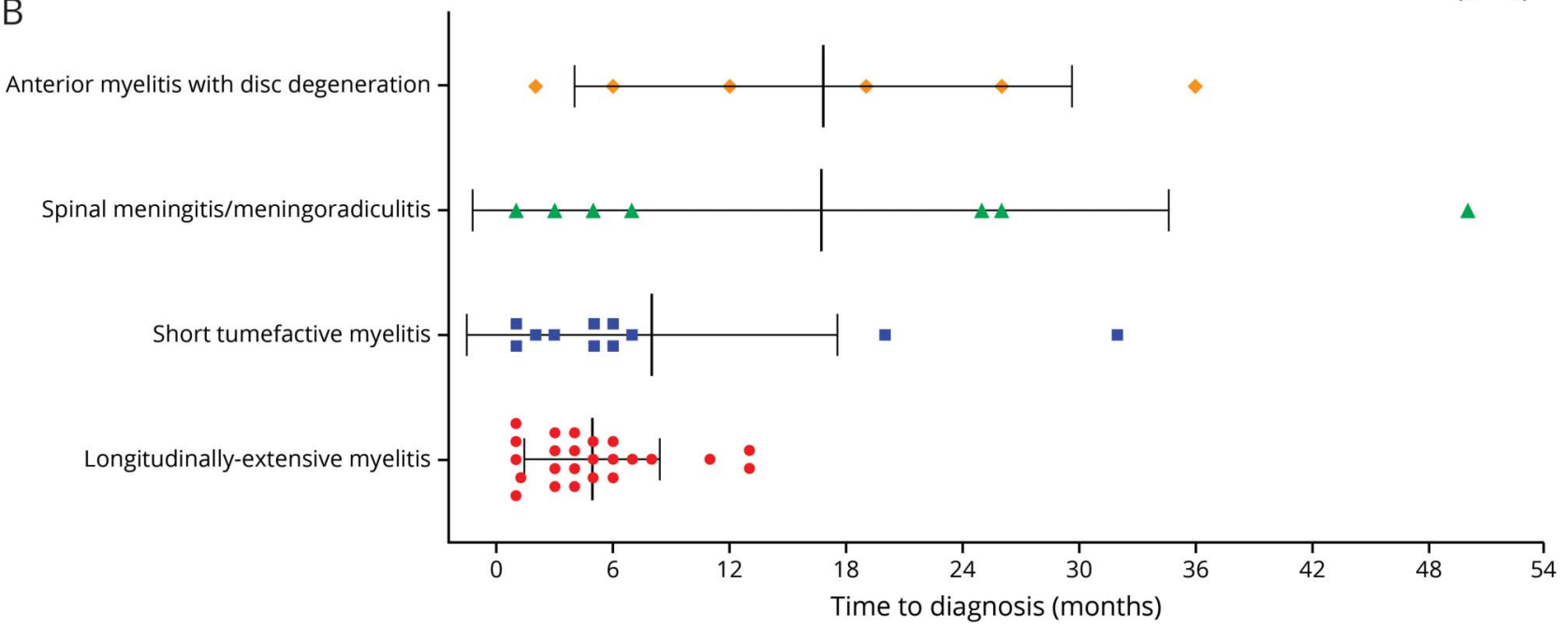

(A) The location of lesions involving the parenchyma of the spinal cord (longitudinally extensive myelitis, short tumefactive myelitis, and anterior myelitis with disc degeneration) is illustrated here, with each patient represented separately. Longitudinally extensive myelitis was predominantly cervicothoracic in distribution, whereas anterior myelitis with disc degeneration was essentially restricted to the thoracic region. (B) Time from symptom onset to diagnosis is recorded here, categorized by the lesion pattern. Only patients without a preexisting diagnosis of sarcoidosis (i.e., in whom myelopathy was the first manifestation of sarcoidosis) are included in this graph (49 of 62 patients, $79 \%$ ).

investigation. However, our findings go somewhat against the hypothesis previously described by Junger et al., ${ }^{26}$ who postulated that the natural history of spinal cord sarcoidosis was a stepwise evolution from leptomeningeal inflammation to parenchymal inflammation to mass-like lesion formation before the inflammatory process abates and the cord atrophies. Specifically, we found that time to diagnosis was frequently many months or years even in patients in whom enhancement was restricted to the meninges. This suggests that the development of parenchymal inflammation is not determined only by time but perhaps by other factors (such as BSCB permeability).

Our study is the largest study to date of the clinical and neuroimaging phenotypes of SAM. However, our work has some limitations. We reviewed clinical MRI studies acquired at multiple facilities, so sequences were not standardized, and some patients did not have imaging of the whole spinal cord. We only analyzed MRI at the time of presentation-future studies are needed to explore lesion evolution and how this correlates with clinical outcomes. As our study was based on the cohort of patients who attended our specialist clinic, there was almost certainly some referral bias toward more diagnostically challenging or severe cases. In addition, even with the application of the most recent diagnostic criteria, neurosarcoidosis remains a diagnosis lacking certainty in most patients (except those who have undergone CNS biopsy). It is possible that some patients who met the criteria for probable neurosarcoidosis actually had a different underlying pathology 
of myelopathy (indeed, we suspect this was a possibility in 1 patient in our cohort who had an atypical nonenhancing spinal cord lesion). Finally, CSF findings were not available for all included patients.

SAM is a rare disabling manifestation of neurosarcoidosis, which typically presents as a chronically evolving myelopathic syndrome with predominant sensory symptoms and often poses a diagnostic challenge-potentially resulting in delayed treatment and irreversible disability. Through detailed neuroimaging review of a large number of cases, we have identified a number of characteristic lesion patterns (all demonstrating subpial and/or meningeal enhancement as a key feature)potentially aiding physicians in the recognition and diagnosis of SAM. Furthermore, our observations regarding postgadolinium enhancement occurring in areas of the spinal cord susceptible to mechanical stress provide interesting clues to the pathophysiology of spinal cord lesions in this elusive disorder.

\section{Study funding}

No targeted funding reported.

\section{Disclosure}

The Johns Hopkins Myelitis and Myelopathy Center is supported by the Bart McLean Fund for Neuroimmunology Research. O.C. Murphy's James T. Lublin Scholarship fellowship is funded by the Siegel Rare Neuroimmune Association. All other authors report no relevant disclosures. Go to Neurology.org/NN for full disclosures.

\section{Publication history}

Received by Neurology: Neuroimmunology \& Neuroinflammation February 7, 2020. Accepted in final form February 28, 2020.

Appendix Authors

\begin{tabular}{|c|c|c|}
\hline Name & Location & Contribution \\
\hline $\begin{array}{l}\text { Olwen C. } \\
\text { Murphy, } \\
\text { MBBCh, } \\
\text { MRCPI }\end{array}$ & $\begin{array}{l}\text { Johns Hopkins } \\
\text { University, } \\
\text { Baltimore, MD }\end{array}$ & $\begin{array}{l}\text { Designed and conceptualized } \\
\text { the study; acquired, analyzed, } \\
\text { and interpreted the data; and } \\
\text { drafted the manuscript for } \\
\text { intellectual content }\end{array}$ \\
\hline $\begin{array}{l}\text { Andrea } \\
\text { Salazar- } \\
\text { Camelo, MD }\end{array}$ & $\begin{array}{l}\text { Johns Hopkins } \\
\text { University, } \\
\text { Baltimore, MD }\end{array}$ & $\begin{array}{l}\text { Acquired, analyzed, and } \\
\text { interpreted the data and revised } \\
\text { the manuscript for intellectual } \\
\text { content }\end{array}$ \\
\hline $\begin{array}{l}\text { Jorge A. } \\
\text { Jimenez, MD }\end{array}$ & $\begin{array}{l}\text { Universidad de } \\
\text { Antioquia, Medellín, } \\
\text { Colombia }\end{array}$ & $\begin{array}{l}\text { Acquired and analyzed the data } \\
\text { and revised the manuscript for } \\
\text { intellectual content }\end{array}$ \\
\hline $\begin{array}{l}\text { Paula } \\
\text { Barreras, MD }\end{array}$ & $\begin{array}{l}\text { Johns Hopkins } \\
\text { University, } \\
\text { Baltimore, MD }\end{array}$ & $\begin{array}{l}\text { Acquired and analyzed the data } \\
\text { and revised the manuscript for } \\
\text { intellectual content }\end{array}$ \\
\hline $\begin{array}{l}\text { Maria I. Reyes, } \\
\text { MD }\end{array}$ & $\begin{array}{l}\text { Johns Hopkins } \\
\text { University, } \\
\text { Baltimore, MD }\end{array}$ & $\begin{array}{l}\text { Acquired and analyzed the data } \\
\text { and revised the manuscript for } \\
\text { intellectual content }\end{array}$ \\
\hline $\begin{array}{l}\text { Maria A. } \\
\text { Garcia, MD }\end{array}$ & $\begin{array}{l}\text { Johns Hopkins } \\
\text { University, } \\
\text { Baltimore, MD }\end{array}$ & $\begin{array}{l}\text { Acquired and analyzed the data } \\
\text { and revised the manuscript for } \\
\text { intellectual content }\end{array}$ \\
\hline
\end{tabular}

Appendix (continued)

\begin{tabular}{lll}
\hline Name & Location & Contribution \\
\hline $\begin{array}{l}\text { David R. } \\
\text { Moller, MD }\end{array}$ & $\begin{array}{l}\text { Johns Hopkins } \\
\text { University, } \\
\text { Baltimore, MD }\end{array}$ & $\begin{array}{l}\text { Revised the manuscript for } \\
\text { intellectual content }\end{array}$ \\
\hline $\begin{array}{l}\text { Edward S. } \\
\text { Chen, MD }\end{array}$ & $\begin{array}{l}\text { Johns Hopkins } \\
\text { University, }\end{array}$ & $\begin{array}{l}\text { Revised the manuscript for } \\
\text { intellectual content }\end{array}$ \\
\hline $\begin{array}{l}\text { Caltimore, MD } \\
\text { Pardo, MD }\end{array}$ & $\begin{array}{l}\text { Johns Hopkins } \\
\text { Bniversity, }\end{array}$ & $\begin{array}{l}\text { Designed and conceptualized } \\
\text { the study; analyzed and } \\
\text { interpreted the data; and } \\
\text { revised the manuscript for } \\
\text { intellectual content }\end{array}$ \\
& & \\
\hline
\end{tabular}

\section{References}

1. Kidd DP. Sarcoidosis of the central nervous system: clinical features, imaging, and CSF results. J Neurol 2018;265:1906-1915. doi: 10.1007/s00415-0188928-2.

2. Fritz D, van de Beek D, Brouwer MC. Clinical features, treatment and outcome in neurosarcoidosis: systematic review and meta-analysis. BMC Neurol 2016;16:220. doi: 10.1186/s12883-016-0741-x.

3. Louveau A, Herz J, Alme MN, et al. CNS lymphatic drainage and neuroinflammation are regulated by meningeal lymphatic vasculature. Nat Neurosci 2018;21:1380-1391. doi: 10.1038/s41593-018-0227-9.

4. Dorman J, Warrior L, Pandya V, et al. Neurosarcoidosis in a public safety net hospital: a study of 82 cases. Sarcoidosis Vasc Dif 2019;36:25-32.

5. Jachiet V, Lhote R, Rufat $P$, et al. Clinical, imaging, and histological presentations and outcomes of stroke related to sarcoidosis. J Neurol 2018;265:2333-2341. doi: 10. 1007/s00415-018-9001-x.

6. Christoforidis GA, Spickler EM, Recio MV, Mehta BM. MR of CNS sarcoidosis: correlation of imaging features to clinical symptoms and response to treatment. AJNR Am J Neuroradiol 1999;20:655-669.

7. Krumholz A, Stern BJ. Sarcoidosis of the nervous system. In: Aminoff AJ, Josephson SA, editors. Aminoff's Neurology and General Medicine. London: Academic Press; 2014:985-1002.

8. Zalewski NL, Flanagan EP, Keegan BM. Evaluation of idiopathic transverse myelitis revealing specific myelopathy diagnoses. Neurology 2018;90:e96-e102. doi: 10. 1212/WNL.0000000000004796.

9. Barreras P, Fitzgerald KC, Mealy MA, et al. Clinical biomarkers differentiate myelitis from vascular and other causes of myelopathy. Neurology 2018;90:e12-e21. doi: 10. 1212/WNL.0000000000004765.

10. Flanagan EP, Kaufmann TJ, Krecke KN, et al. Discriminating long myelitis of neuromyelitis optica from sarcoidosis. Ann Neurol 2016;79:437-447. doi: 10.1002/ana. 24582.

11. Zalewski NL, Krecke KN, Weinshenker BG, et al. Central canal enhancement and the trident sign in spinal cord sarcoidosis. Neurology 2016;87:743-744. doi: 10.1212/ WNL.0000000000002992.

12. Cohen-Aubart F, Galanaud D, Grabli D, et al. Spinal cord sarcoidosis: clinical and laboratory profile and outcome of 31 patients in a case-control study. Medicine (Baltimore) 2010;89:133-140. doi: 10.1097/MD.0b013e3181d5c6b4.

13. Durel C, Marignier R, Maucort-Boulch D, et al. Clinical features and prognostic factors of spinal cord sarcoidosis: a multicenter observational study of 20 BIOPSY-PROVEN patients. J Neurol 2016;263:981-990. doi: 10.1007/s00415016-8092-5.

14. Stern BJ, Royal W, Gelfand JM, et al. Definition and consensus diagnostic criteria for neurosarcoidosis: from the neurosarcoidosis consortium consensus group. JAMA Neurol 2018;75:1546-1553. doi: 10.1001/jamaneurol.2018.2295.

15. Banks JL, Marotta CA. Outcomes validity and reliability of the modified Rankin scale: implications for stroke clinical trials: a literature review and synthesis. Stroke 2007;38: 1091. doi: 10.1161/01.STR.0000258355.23810.c6.

16. Kirshblum SC, Burns SP, Biering-Sorensen F, et al. International standards for neurological classification of spinal cord injury (revised 2011). J Spinal Cord Med 2011; 34:535-546. doi: 10.1179/204577211X13207446293695.

17. Boban J, Thurnher M. Ventral-subpial enhancement in spinal cord sarcoidosis: a braid-like sign. Neurology 2019;92:236-238. doi: 10.1212/WNL. 0000000000006857.

18. Arkema EV, Cozier YC. Epidemiology of sarcoidosis: current findings and future directions. Ther Adv Chronic Dis 2018;9:227-240. doi: 10.1177/ 2040622318790197.

19. Kaiser Y, Eklund A, Grunewald J. Moving target: shifting the focus to pulmonary sarcoidosis as an autoimmune spectrum disorder. Eur Respir J 2019;54:1802153. doi: 10.1183/13993003.021532018.

20. Lareau CA, Adrianto I, Levin AM, Iannuzzi MC, Rybicki BA, Montgomery CG. Fine mapping of chromosome 15q25 implicates ZNF592 in neurosarcoidosis patients. Ann Clin Transl Neurol 2015;2:972-977. doi: 10.1002/acn3.229. 
21. Chen HI, Lang S, Coyne TM, Malhotra NR, Schuster JM. Intramedullary spinal sarcoidosis masquerading as cervical stenosis. World Neurosurg 2013;80:375. doi: 10. 1016/j.wneu.2012.09.022.

22. Shiraishi $Y$, Kimura A, Seichi A, et al. Multifocal extramedullary spinal sarcoid lesions mimicking leptomeningeal metastasis. J Orthop Sci 2013;18:343-346. doi: 10.1007/ s00776-011-0164-x.

23. Beros V, Houra K, Rotim K, Kovac D, Cupić H. Thoracic intramedullary sarcoidosis mimicking an intramedullary tumor. Coll Antropol 2008;32:645-647.

24. Joubert B, Chapelon-Abric C, Biard L, et al. Association of prognostic factors and immunosuppressive treatment with long-term outcomes in neurosarcoidosis. JAMA Neurol 2017;74:1336-1344. doi: 10.1001/jamaneurol.2017.2492.

25. Cohen Aubart F, Bouvry D, Galanaud D, et al. Long-term outcomes of refractory neurosarcoidosis treated with infliximab. J Neurol 2017;264:891-897. doi: 10.1007/ s00415-017-8444-9.

26. Junger SS, Stern BJ, Levine SR, Sipos E, Marti-Masso JF. Intramedullary spinal sarcoidosis: clinical and magnetic resonance imaging characteristics. Neurology 1993;43: 333-337.

27. Cohen-Gadol AA, Zikel OM, Miller GM, Aksamit AJ, Scheithauer BW, Krauss WE. Spinal cord biopsy: a review of 38 cases. Neurosurgery 2003;52:806-816. doi: 10 . 1227/01.neu.0000053223.77641.5e.

28. Sohn M, Culver DA, Judson MA, Scott TF, Tavee J, Nozaki K. Spinal cord neurosarcoidosis. Am J Med Sci 2014;347:195-198. doi: 10.1097/MAJ. Ob013e3182808781.

29. Flanagan EP, Krecke KN, Marsh RW, Giannini C, Keegan BM, Weinshenker BG. Specific pattern of gadolinium enhancement in spondylotic myelopathy. Ann Neurol 2014;76:54-65. doi: 10.1002/ana.24184.

30. Sakushima K, Yabe I, Nakano F, et al. Clinical features of spinal cord sarcoidosis: analysis of 17 neurosarcoidosis patients. J Neurol 2011;258:2163-2167. doi: 10.1007/ s00415-011-6080-3.
31. Kobayashi S, Nakata W, Sugimoto H. Spinal magnetic resonance imaging manifestations at neurological onset in Japanese patients with spinal cord sarcoidosis. Intern Med 2013;52:2041-2050.

32. Sakushima K, Yabe I, Shiga T, et al. FDG-PET SUV can distinguish between spinal sarcoidosis and myelopathy with canal stenosis. J Neurol 2011;258:227-230. doi: 10 . 1007/s00415-010-5729-7.

33. Karadimas SK, Erwin WM, Ely CG, Dettori JR, Fehlings MG. Pathophysiology and natural history of cervical spondylotic myelopathy. Spine 2013;38:21. doi: 10.1097/ BRS.0b013e3182a7f2c3.

34. Tetreault L, Goldstein CL, Arnold P, et al. Degenerative cervical myelopathy: a spectrum of related disorders affecting the aging spine. Neurosurgery 2015;77(suppl 4):51. doi: 10.1227/NEU.0000000000000951.

35. Hebel R, Dubaniewicz-Wybieralska M, Dubaniewicz A. Overview of neurosarcoidosis: recent advances. J Neurol 2015;262:258-267. doi: 10.1007/s00415-0147482-9.

36. Meyer JS, Foley JM, Campagna-Pinto D. Granulomatous angiitis of the meninges in sarcoidosis. AMA Arch Neurol Psychiatry 1953;69:587-600. doi: 10.1001/archneurpsyc.1953.02320290039005

37. Levivier M, Brotchi J, Balériaux D, Pirotte B, Flament-Durand J. Sarcoidosis presenting as an isolated intramedullary tumor. Neurosurgery 1991;29:271-276. doi: 10 . 1097/00006123-199108000-00020.

38. Nagai H, Ohtsubo K, Shimada H. Sarcoidosis of the spinal cord. report of an autopsy case and review of the literature. Acta Pathol Jpn 1985;35:1007-1022.

39. Miura M, Kato S, von Lüdinghausen M. Lymphatic drainage of the cerebrospinal fluid from monkey spinal meninges with special reference to the distribution of the epidural lymphatics. Arch Histol Cytol 1998;61:277-286. doi: 10.1679/aohc.61.277.

40. Wu Y, Zhong L, Geng J. Neuromyelitis optica spectrum disorder: pathogenesis, treatment, and experimental models. Mult Scler Relat Dis 2019;27:412-418. doi: 10 1016/j.msard.2018.12.002. 


\section{Neurology \\ Neuroimmunology \& Neuroinflammation}

Clinical and MRI phenotypes of sarcoidosis-associated myelopathy

Olwen C. Murphy, Andrea Salazar-Camelo, Jorge A. Jimenez, et al.

Neurol Neuroimmunol Neuroinflamm 2020;7;

DOI 10.1212/NXI.0000000000000722

This information is current as of April 8, 2020

\section{Updated Information \& Services}

References

Citations

Subspecialty Collections

Permissions \& Licensing

Reprints including high resolution figures, can be found at:

http://nn.neurology.org/content/7/4/e722.full.html

This article cites 39 articles, 3 of which you can access for free at: http://nn.neurology.org/content/7/4/e722.full.html\#\#ref-list-1

This article has been cited by 8 HighWire-hosted articles: http://nn.neurology.org/content/7/4/e722.full.html\#\#otherarticles

This article, along with others on similar topics, appears in the following collection(s):

All Spinal Cord

http://nn.neurology.org//cgi/collection/all_spinal_cord MRI

http://nn.neurology.org//cgi/collection/mri

Transverse myelitis

http://nn.neurology.org//cgi/collection/transverse_myelitis

Information about reproducing this article in parts (figures,tables) or in its entirety can be found online at:

http://nn.neurology.org/misc/about.xhtml\#permissions

Information about ordering reprints can be found online: http://nn.neurology.org/misc/addir.xhtml\#reprintsus

Neurol Neuroimmunol Neuroinflamm is an official journal of the American Academy of Neurology.

Published since April 2014, it is an open-access, online-only, continuous publication journal. Copyright

Copyright $\odot 2020$ The Author(s). Published by Wolters Kluwer Health, Inc. on behalf of the American

Academy of Neurology.. All rights reserved. Online ISSN: 2332-7812.

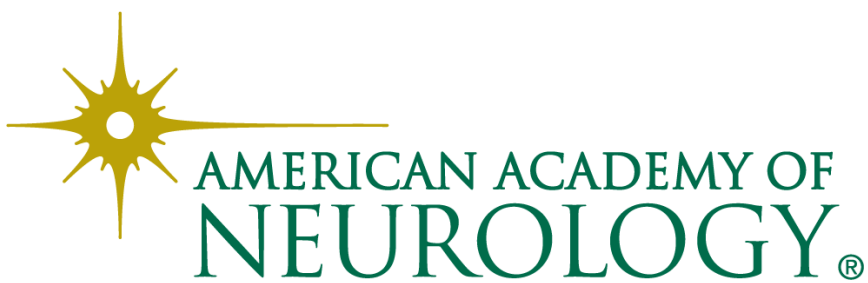

